( 2020 , The Authors. Published by Elsevier Inc. and Fass Inc. on behalf of the American Dairy Science Association ${ }^{\circledR}$. This is an open access article under the CC BY-NC-ND license (http://creativecommons.org/licenses/by-nc-nd/4.0/).

\title{
Body size in relation to cubicle dimensions affects lying behavior and joint lesions in dairy cows
}

\author{
N. Dirksen, ${ }^{1,2}$ L. Gygax, ${ }^{1,3} \odot$ I. Traulsen, ${ }^{2}$ B. Wechsler, ${ }^{1} \oplus$ and J.-B. Burla ${ }^{1 *}$ (이 \\ ${ }^{1}$ Centre for Proper Housing of Ruminants and Pigs, Federal Food Safety and Veterinary Office FSVO, Agroscope Tänikon, 8356 Ettenhausen, \\ Switzerland \\ ${ }^{2}$ Livestock Systems, Department of Animal Science, Georg-August-Universität Göttingen, Albrecht-Thaer-Weg 3, 37075 Göttingen, Germany \\ ${ }^{3}$ Animal Husbandry and Ethology, Albrecht Daniel Thaer-Institute of Agricultural and Horticultural Sciences, Faculty of Life Sciences, \\ Humboldt-Universität zu Berlin, Unter den Linden 6, 10099 Berlin, Germany
}

\section{ABSTRACT}

Adequate cubicle dimensions are important for dairy cows to allow for species-appropriate lying behavior. Even though cow body size has increased in the last 2 decades, the cubicle dimensions of housing systems built many years ago have not been adjusted on most farms. Therefore, cows may be impaired in their lying behaviors, and thus the present study aimed to determine the influence of the ratio of body size to cubicle dimension on lying behavior and joint lesions. We investigated the lying behavior of 144 cows with withers heights of 140 to $163 \mathrm{~cm}$ on 8 Swiss dairy farms. Among the farms, the cubicle bed length varied from 187 to $200 \mathrm{~cm}$ and lunge space length varied from 47 to $202 \mathrm{~cm}$. Specific behaviors of lying down and standing up movements, as well as lying positions, were observed on $3 \mathrm{~d}$ per farm. As outcome variables, the occurrences of these behaviors were calculated as proportions in relation to the respective total number of observations per cow. In addition, the presence of joint lesions was scored once. Data of the individual cows were analyzed in relation to the given cubicle dimensions on the farms by mixed-effects models. The bed length ratio [bed length $(\mathrm{cm})$ on the farm/withers height $(\mathrm{cm})$ of the observed cow] and the lunge space ratio [lunge space length $(\mathrm{cm})$ on the farm/withers height $(\mathrm{cm})$ of the observed cow] were used as explanatory variables. An increase in the bed length ratio was associated with decreased proportions of lying down movements with (1) repeated head pendulum movements, (2) repeated stepping with front legs, and (3) hitting against cubicle elements; decreased proportions of standing up movements with (1) shifting backward, (2) hesitant head lunge movements, and (3) hitting against cubicle elements; and an increased proportion of lying positions without physical contact with

Received February 11, 2019.

Accepted April 28, 2020.

*Corresponding author: joan-bryce.burla@agroscope.admin.ch cubicle elements. An increase in the lunge space ratio was associated with a decreased proportion of standing up movements with sideways directed head lunge movements. Furthermore, an increase in the bed length ratio decreased the proportion of cows with tarsal joint lesions. To summarize, the lying behavior of large-framed cows was clearly modified given the cubicle dimensions in use on the study farms. In view of the consistency of the obtained results, we recommend adjusting the dimensions of cubicles so that they are suitable for cows whose body size meets the breeding goals of the farm. Key words: withers height, bed length, lunge space length, lying down and standing up movement

\section{INTRODUCTION}

In contrast to pasture or husbandry systems with deep litter, cubicles provide restricted space for recumbency. The dimensions of cubicles are determined by the fixed cubicle elements, including the curb board, brisket board, neck rail, front rail (or wall), and partitions. These elements control the cows' positions during standing and lying to keep the bed surface and animals clean (Fregonesi et al., 2009). Cubicle dimensions are a compromise between correctly positioning the cows and ensuring their comfort. Consequently, cubicle elements restrict cows in their lying position and in their freedom of movement during lying down and standing up movements. However, the extent of the restriction is determined by the relationship between the cubicle dimensions and the body size of the individual cow.

Different aspects of lying behavior have been used to assess cubicle design factors. A commonly used indicator is time spent lying down (Haley et al., 2000; Gygax et al., 2005; O'Driscoll et al., 2009). However, daily lying duration is also influenced by cow-individual factors such as parity (Westin et al., 2016), DIM (Bewley et al., 2010), BCS (Westin et al., 2016), rank (Galindo and Broom, 2000), or health [e.g., lameness (Weigele et al., 2018), mastitis (Siivonen et al., 2011), or joint 
lesions (Charlton et al., 2016)]. In contrast, lying down and standing up movements are performed according to innate movement patterns (Lidfors, 1989). Nonetheless, these patterns may change in unsuitable housing conditions (Kämmer and Schnitzer, 1975; Ceballos et al., 2004). When subjected to severe space restrictions, cows may show non-species-specific lying down and standing up movements as they first lower their hindquarters before dropping onto their carpal joints ("dog-sitting") when lying down, or first raise their forequarters before rising from the tarsal joints ("horselike") when standing up (Lidfors, 1989). However, even under less severe space restrictions, cows may still show changed movement patterns. For example, Haley et al. (2000) found that cows kept in tiestalls showed more interrupted attempts at lying down and performed more investigation of the lying area, such as repeated sweeping head movements while sniffing the ground before lying down, when compared with cows kept in loose housing. Kämmer (1981) reported that unsuitably designed cubicles cause repeated stepping in place as the cows change the weight on their forelegs while initiating lying down movements. Moreover, if cubicles provided insufficient lunge space for a smooth and straight forward directed head lunge for standing up, Kämmer and Tschanz (1975) observed 2 types of altered movement patterns: either the animals lifted their heads straight upward in the intermission phase of the standing up movement, resulting in a hesitant or repeated head lunge movement, or they directed the head lunge sideways. Accordingly, shifting backward before or during standing up, presumably to gain more lunge space, has also been used as an indicator of inappropriate cubicle design (Potterton et al., 2011). Finally, the cows' positions during recumbency is also affected by the cubicle dimensions as well as the position of the cubicle elements. If the cubicle design is inadequate, the cow is more likely to come into contact with the curb board, the brisket board, or the partitions while in the recumbent position. Accordingly, the presence of a curb board increases the risk for tarsal joint lesions (Weary and Taszkun, 2000; Fulwider et al., 2007), but the occurrence of lesions decreases with a larger distance between neck rail and curb board (Zaffino Heyerhoff et al., 2014). Similarly, Kielland et al. (2009) reported an increased risk of tarsal and carpal joint lesions in cows when the cubicle length was too short.

In the last 2 decades, the body size of dairy cows has increased considerably due to breeding for higher feed intake and milk production (Sieber et al., 1988; Schönmuth and Löber, 2006). As an example, the average height of the Swiss Holstein population (Holstein and Red Holstein cows from the third lactation onward) increased by $6.3 \mathrm{~cm}$, from $144.3 \mathrm{~cm}$ in 1996 to $150.6 \mathrm{~cm}$ in 2011, and the largest $10 \%$ of cows of the population in 2011 had an average height of $156.0 \mathrm{~cm}$ (Swissherdbook, Zollikofen, Switzerland, unpublished data). German Holstein cows increased in height by $8 \%$, or $11 \mathrm{~cm}$, between 1988 and 2005 (Rudolphi, 2008).

The actual space availability for individual cows is strongly dependent on their body size in relation to the given cubicle dimensions. Consequently, when the cubicle dimensions of housing systems built many years ago have not been adjusted to the increase in body size, large-framed cows have less space available than the smaller cows of the past. The aim of the present study was to examine the lying behavior and the presence of lesions at the carpal and tarsal joints of dairy cows of varying body size in relation to the given cubicle dimensions on 8 farms.

\section{MATERIALS AND METHODS}

\section{Study Population}

The study was conducted between May and July 2017 on 8 dairy farms in Switzerland. The farms participated voluntarily and were recruited through personal contacts. Farmers were contacted and asked if they were interested in participating and if their herd had a sufficient number of cows (10 or more) with a withers height between 140 and $150 \mathrm{~cm}$ and $>150 \mathrm{~cm}$. If so, the farms were visited to ensure that the housing systems in general and the cubicles in particular were in accordance with the Swiss animal welfare legislation (FSVO, 2008).

The farms' housing systems provided both wall-facing and head-to-head deep-bedded cubicles ( $\geq 1$ cubicle per cow). Bedding materials were based on a lime-straw mixture and had a depth of 6 to $16 \mathrm{~cm}$ (mean \pm SD $=10.9 \pm 3.7$ ). The cubicles were maintained (i.e., removing feces and leveling of bedding material) 2 or 3 times daily. The herds consisted of 45 to 120 (mean $\pm \mathrm{SD}=64.1 \pm 24.8$ ) hornless lactating cows of the breeds Brown Swiss, Holstein-Friesian, Red Holstein, Fleckvieh, and their crossbreeds.

Ethical approval for the study was obtained from the Veterinary Office of the Canton Thurgau (Switzerland; TG01/17, Approval No. 28874), and the entire data collection was performed by 1 person (N. Dirksen). Based on a visual health assessment and consultation with the farmers, only cows in good general condition and without signs of lameness or mastitis participated in the study. On each farm, 6 to 10 cows with a withers height $>150 \mathrm{~cm}$ were selected as focus animals, along with an equivalent number of cows with a withers height 
Table 1. Measurements of the body size and the ratios of cubicle dimension to body size of the observed focus animals $(\mathrm{n}=144)$; the bed length ratio and the lunge space ratios were used as explanatory variables in the statistical models

\begin{tabular}{lc}
\hline Measurement & Mean $\left(\mathrm{SE}_{\text {between-farms }} / \mathrm{SE}_{\text {within-farm }} \text {, range }\right)^{1}$ \\
\hline Withers height $^{2}(\mathrm{~cm})$ & $149.3(1.4 / 5.2,140.0-163.0)$ \\
Diagonal trunk length $(\mathrm{cm})$ & $177.4(0.9 / 6.8,161.0-193.0)$ \\
Rump width $(\mathrm{cm})$ & $1.29(0.02 / 0.04,1.20-1.40)$ \\
Bed length ratio & $0.52(0.15 / 0.02,0.35-0.75)$ \\
Lunge space ratio, wall-facing cubicles ${ }^{4}$ & $0.64(0.49 / 0.03,0.30-1.42)$ \\
Lunge space ratio, head-to-head cubicles ${ }^{4}$ & \\
${ }^{1}$ Means and between-farms and within-farm $\mathrm{SE}$ of the measurements for each body size and each ratio of \\
cubicle dimension to body size were estimated using a linear mixed-effects model with the respective measure- \\
ment as the response variable, the intercept as the only fixed effect, and the farm as the random effect. Means \\
were reflected by the model estimate of the intercept and the residual, and farm variation corresponded to the \\
within- and between-farms SE. \\
${ }^{2}$ Cows with a withers height $>150 \mathrm{~cm}$ (n $\left.=72\right)$ and the equivalent number of cows with a withers height in the \\
range of $140-150 \mathrm{~cm}(\mathrm{n}=72)$ were selected on each farm. \\
${ }^{3}$ Bed length $(\mathrm{cm})$ on the farm divided by withers height $(\mathrm{cm})$ of the observed cow. \\
${ }^{4}$ Lunge space length $(\mathrm{cm})$ on the farm divided by withers height $(\mathrm{cm})$ of the observed cow.
\end{tabular}

in the range of 140 to $150 \mathrm{~cm}$ (Table 1). The number of focus animals varied because some herds had fewer than 10 cows with a height $>150 \mathrm{~cm}$. In total, data were collected from 144 cows (mean $\pm \mathrm{SD}=18.0 \pm 2.8$ cows/farm), including 51 Brown Swiss (withers height 140-156 cm) on 5 farms, 52 Holstein-Friesian (142-163 $\mathrm{cm})$ on 6 farms, and 41 Red Holstein or Fleckvieh or their crossbreeds (141-158 cm) on 7 farms. Detailed data on the variation in body size dependent on the breed are shown in Supplemental Figure S1 (https:// doi.org/10.3168/jds.2019-16464).

\section{Cow Body Size and Cubicle Dimensions}

Measurements of cow body size and cubicle dimensions were taken on the day before the behavioral observations started on the respective farm. These measurements formed the basis for calculating the explanatory variables (see "Data and Statistical Analyses" below).

Each cow's withers height, diagonal trunk length (shoulder point to pin bone), and rump width (hook bone to hook bone) were measured (Table 1; Supplemental Figure S1; https://doi.org/10.3168/jds.2019 -16464) by hand using a common cow stick measure. Measurements were taken when the cow was standing with its legs square and head up such that the intercornual protuberance (protuberantia intercornualis) was on the level of the withers. For this purpose, the cows were fixed in the headlock of the feed fence ( 7 farms) or held with a cow rope halter ( 1 farm). The cows were individually marked with animal marking spray (Raidex, Arndt Europadiscount, Hochdorf, Germany) for identification during direct observations.

Cubicle dimensions were taken using a laser distance measuring device (Leica DISTO A8, Leica Geosystems
AG, Heerbrugg, Switzerland). On each farm, 5 wallfacing cubicles and 5 head-to-head cubicles distributed across the barn were randomly selected for measurements. The measured values for each cubicle type were averaged and used as the cubicle dimensions for the respective farms (Table 2 ).

\section{Lying Behavior and Joint Lesions}

The cows were observed directly between 0800 and $1600 \mathrm{~h}$ on 3 consecutive days on each farm. The observation periods varied from 4.5 to $6 \mathrm{~h} / \mathrm{d}$, depending on the milking times on the farm and the pasture access on a given observation day. The observations of lying behavior, lying positions, and joint lesions served as the basis for calculating the outcome variables (see "Data and Statistical Analyses" below). The lying behavior was divided into 2 sets of models: one applied to variables used to quantify different aspects of lying down and the other to standing up movements.

Lying down and standing up movements of the cows were observed continuously (all event sampling; Martin and Bateson, 1993) according to the ethogram described in Table 3. The lying position of recumbent cows and the associated cubicle type were recorded every $20 \mathrm{~min}$ (scan sampling; Martin and Bateson, 1993; details in Table 4). This recording included whether the cow was lying without physical contact with cubicle elements or with physical contact with (1) the curb board, (2) the brisket board, or (3) the partitions.

The cows' carpal and tarsal joints were examined for lesions while taking the measurements of cow body size. Each of the 4 joints was assigned a lesion score (scoring system adapted from Norring et al., 2008); hair alterations or areas of hair loss (including calluses) were 


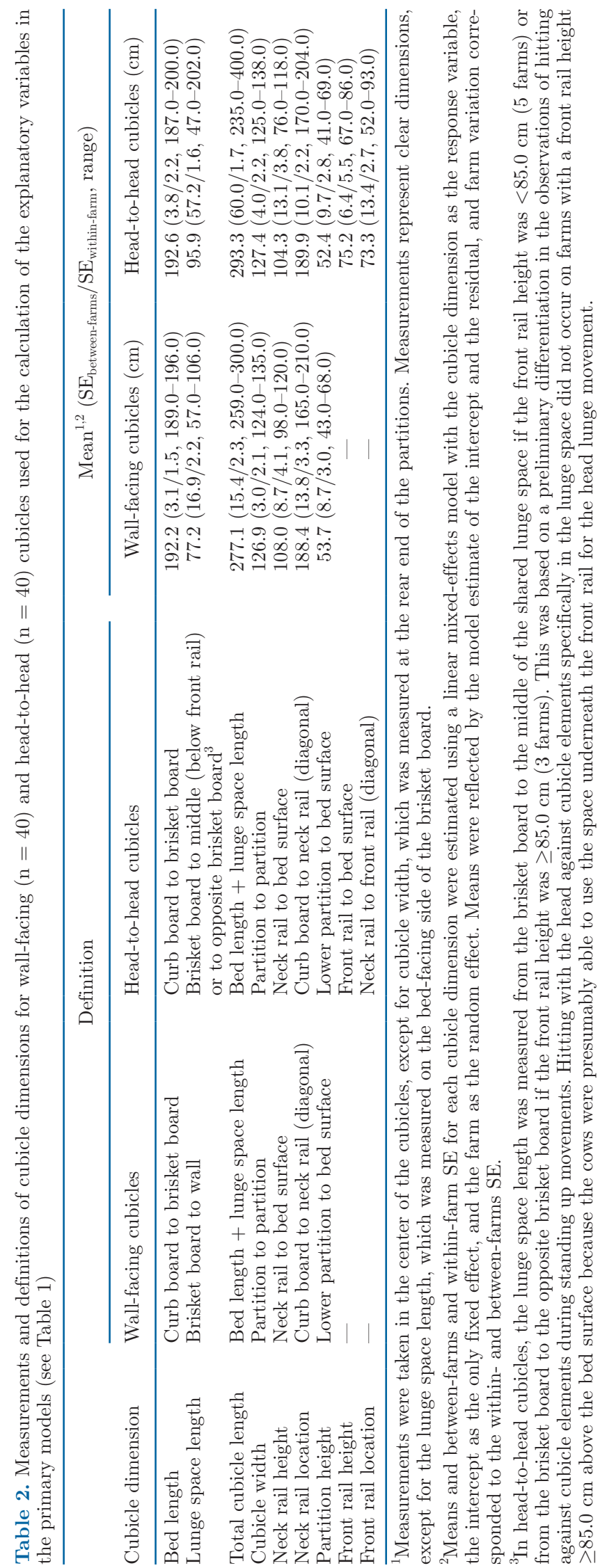

scored as minor lesions, skin abrasions as moderate lesions, and enlarged lumps as severe lesions. If the lesion score of the left and right joint of a cow differed, the higher score was recorded for the respective type of joint.

\section{Data and Statistical Analyses}

Statistical analyses were conducted in $\mathrm{R}$ (version 3.5.2; R Core Team, 2017).

Determination of Explanatory Variables. To reduce the number of variables describing cow body size and cubicle dimensions and to determine a small set of explanatory variables for the statistical analyses, principal component analyses (PCA; for a description of the application of the method see Abdi and Williams, 2010) were applied. The PCA for the measurements of cow body size showed that withers height, diagonal trunk length, and rump width loaded strongly on the first principal component, which explained $75.2 \%$ of the variance (all with loadings $\geq 0.55$ ). The withers height was selected as the representative measurement for cow body size because it is widely used in practice.

The PCA for the measurements of cubicle dimensions showed that they loaded strongly on the first 2 principal components, which together explained $71.8 \%$ of the variance (principal component 1: total cubicle length, lunge space length, neck rail location, front rail height with loadings $\geq 0.44$; principal component 2 : bed length, cubicle width, neck rail height with loadings $\geq 0.52$ ). The lunge space length and bed length were selected as the representative measurements for cubicle dimensions.

To analyze the effects of the withers height of an individual cow in relation to a given bed length and lunge space length found on the different farms (i.e., to represent the actual space available to each cow), 3 explanatory variables were calculated (Table 1):

- Bed length ratio = bed length $(\mathrm{cm}) /$ withers height $(\mathrm{cm})$. For example, a bed length of $195 \mathrm{~cm}$ corresponds to a ratio of 1.39 for a cow with a withers height of $140 \mathrm{~cm}$, a ratio of 1.30 for a cow with $150 \mathrm{~cm}$, and a ratio of 1.22 for a cow with $160 \mathrm{~cm}$.

- Lunge space ratio = lunge space length $(\mathrm{cm}) /$ withers height $(\mathrm{cm})$ calculated for wall-facing cubicles. For example, a lunge space length of 75 $\mathrm{cm}$ corresponds to a ratio of 0.54 for a cow with a withers height of $140 \mathrm{~cm}$, a ratio of 0.50 for a cow with $150 \mathrm{~cm}$, and a ratio of 0.47 for a cow with $160 \mathrm{~cm}$.

- Lunge space ratio = lunge space length $(\mathrm{cm}) /$ withers height $(\mathrm{cm})$ calculated for head-to-head cubicles. 
Analyses of the Outcome Variables. The effects of the continuous explanatory variables (bed length ratio, lunge space ratio, and their interaction) on the outcome variables were analyzed using linear mixedeffects models and generalized linear mixed-effects models (lmer and glmer, package lme4; Bates et al., 2015; Table 4). Model assumptions (normal distribution, homoscedasticity) were checked by graphical analysis of the residuals, and the outcome variables were transformed if necessary (Table 4). $P$-values were calculated using a parametric bootstrap (PBmodcomp, package pbkrtest; Halekoh and Højsgaard, 2014) with 1,000 samples. The interaction between bed length ratio and lunge space ratio never reached a low $P$-value $(P=0.064)$. Therefore, the interaction was dropped from all models, and the models presented are main-effects models including bed length ratio and lunge space ratio (Table 4) as the sole explanatory variables.

For lying down movements, standing up movements, and lying positions, observations were summarized per cow and separately for wall-facing and head-to-head cubicles. The relative proportion of each movement or position, as defined in the ethogram (Table 3), was calculated in relation to the total number of observations (Table 4). For example, the proportion of hesitant head lunge movements was calculated in relation to the cow's total number of standing up movements, separately for wall-facing cubicles and head-to-head cubicles. Accordingly, each cow provided 2 data points per outcome variable. To account for this approach, the random effect included the cow nested in the farm (for variance components, see Table 4). Each cow in each cubicle type had a different number of total observations of lying down movements, standing up movements, and lying positions on which the outcome variables were based. Therefore, each data point was weighed by the number of total observations used to calculate the respective outcome variable (using the parameter weights; Bates et al., 2015).

For lesions on carpal and tarsal joints, each cow provided 1 data point per outcome variable. Here, the fixed effects in the full models included the bed length ratio of head-to-head cubicles (numeric), the lunge space ratio of wall-facing cubicles (numeric), and the lunge space ratio of head-to-head cubicles (numeric) as main effects, as well as the interactions of the bed length ratio with each of the lunge space ratios. This selection was made due to the great differences in the cow-specific lunge space ratios for wall-facing and headto-head cubicles, whereas the bed length ratios varied only marginally between the 2 cubicle types (Table 2 ).

Table 3. Ethogram of observed movements during lying down and standing up

\begin{tabular}{|c|c|c|}
\hline Item & Behavior & Definition \\
\hline \multirow{5}{*}{ Lying down movements } & $\begin{array}{l}\text { Termination of lying down movement (yes/ } \\
\text { no) }\end{array}$ & $\begin{array}{l}\text { Carpal joints touch the ground, but the lying down } \\
\text { movement is then terminated by raising from the carpal } \\
\text { joints }\end{array}$ \\
\hline & $\begin{array}{l}\text { Repeated head pendulum movements (yes/ } \\
\text { no) }\end{array}$ & $\begin{array}{l}\text { Head lowered and sweeping sideways (while sniffing the bed } \\
\text { surface) more than } 2 \text { times before the lying down movement }\end{array}$ \\
\hline & Repeated stepping with hind legs (yes/no) & $\begin{array}{l}\text { Stepping in place with hind legs more than } 2 \text { times before } \\
\text { the lying down movement }\end{array}$ \\
\hline & Pawing (yes/no) & Pawing with front leg just before the lying down movement \\
\hline & Hitting against cubicle elements (yes/no) & Physical contact with cubicle elements (e.g., front rail, neck \\
\hline \multirow[t]{3}{*}{ Standing up movements } & $\begin{array}{l}\text { Species-specific standing up movement }{ }^{2} \\
\text { (ves } / \text { no) }\end{array}$ & $\begin{array}{l}\text { First lifting hindquarters during a smooth forward head } \\
\text { lunge movement and then raising from carpal joints }\end{array}$ \\
\hline & Head lunge movement hesitant $\left(\right.$ yes $/$ no $^{3}$ ) & $\begin{array}{l}\text { Hesitant, interrupted, or repeated motion of the head during } \\
\text { the head lunge movement }\end{array}$ \\
\hline & $\begin{array}{l}\text { Head lunge movement directed sideways } \\
\left(\text { yes } / \mathrm{no}^{4}\right)\end{array}$ & $\begin{array}{l}\text { Head lunge movement is directed sideways by bending the } \\
\text { head and neck to the side }\end{array}$ \\
\hline
\end{tabular}

\footnotetext{
${ }^{1}$ A lying down movement was non-species-specific if the cow first lowered the hindquarters and then the forequarters ("dog-sitting").

${ }^{2}$ A standing up movement was non-species-specific if the cow first raised the forequarters and then the hindquarters ("horse-like").

${ }^{3} \mathrm{No}=$ the head lunge movement was carried out smoothly and with a continuous motion of the head.

${ }^{4} \mathrm{No}=$ the head lunge movement was directed straight forward.
} 


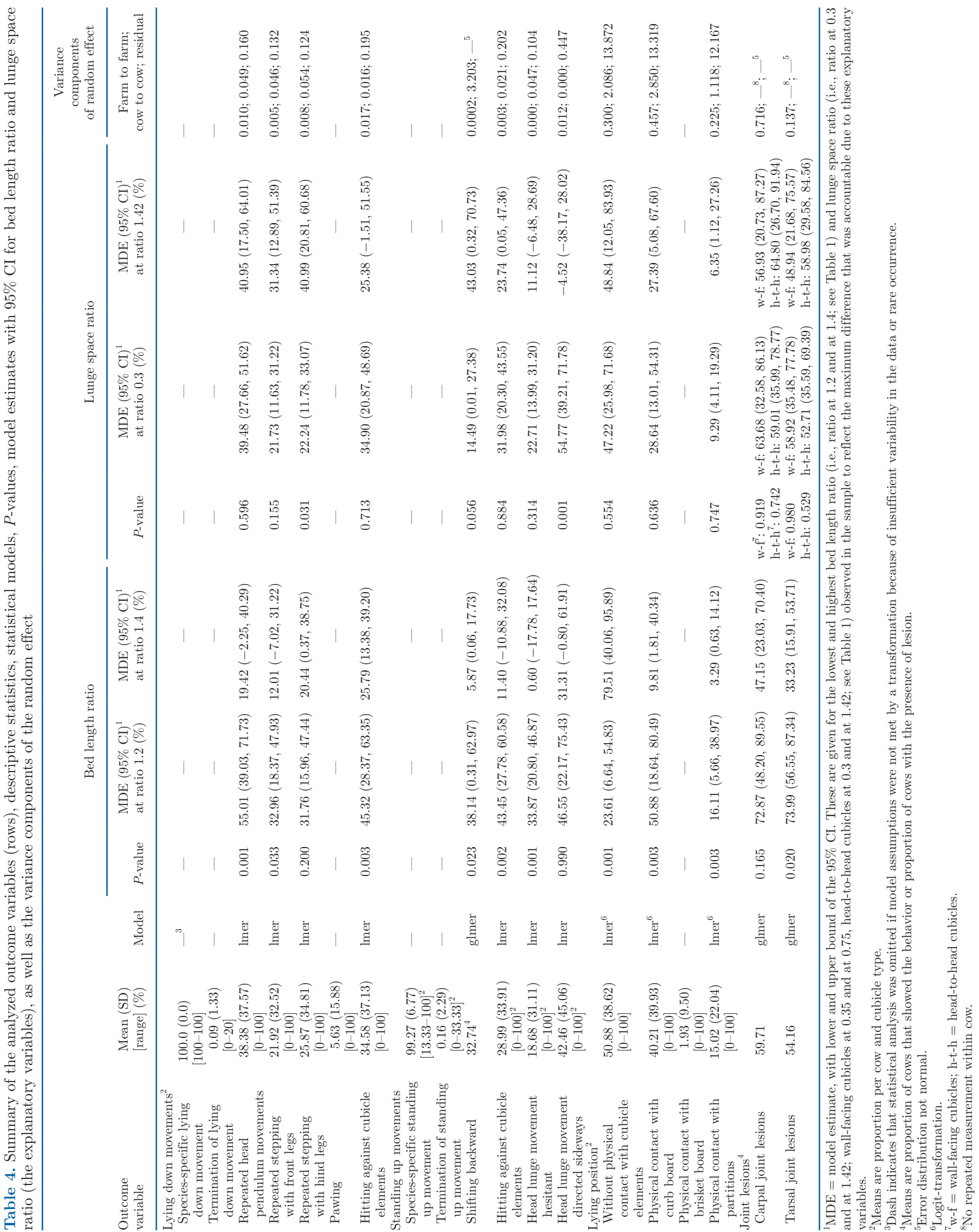


The random effect included the farm (for variance components, see Table 4).

\section{RESULTS}

In total, 703 lying down movements (mean $\pm \mathrm{SD}$ $=5.06 \pm 1.93 / \mathrm{cow})$ and 655 standing up movements $($ mean $\pm \mathrm{SD}=4.71 \pm 1.97 / \mathrm{cow})$ were observed in 142 cows (2 individuals were never observed during lying down and standing up movements). In addition, 3,161 lying positions (mean $\pm \mathrm{SD}=21.95 \pm 9.80 / \mathrm{cow}$ ) and joint lesions were recorded in 144 cows.

\section{Lying Down Movements}

Overall, all $703(100 \%)$ of the observed lying down movements were species-specific and $1 / 703$ was terminated. Within the range of the cubicle dimensions recorded, an increase in the bed length ratio was associated with a decreased proportion of repeated head pendulum movements (Figure 1A), repeated stepping with front legs (Figure 1B), and hitting against cubicle elements (Figure 1C) by as much as $35.59 \%, 20.95 \%$, and $30.32 \%$, respectively, whereas an effect of the lunge space ratio on these behaviors was not statistically supported (Table 4). An increase in the lunge space ratio was associated with an increased proportion of repeated stepping with hind legs by up to $18.76 \%$, whereas an effect of the bed length ratio on this behavior was not statistically supported (Table 4).

\section{Standing Up Movements}

Overall, 640/655 (98\%) of the observed standing up movements were species-specific and $1 / 655$ was terminated. An increase in the bed length ratio was associated with a decreased proportion of cows shifting backward by as much as $32.27 \%$ and a decreased proportion of hitting against cubicle elements (Figure 1D) or hesitant head lunge movements (Figure 1E) by as much as $32.05 \%$ and $33.29 \%$, respectively, whereas an effect of the lunge space ratio on these behaviors was not statistically supported (Table 4). An increase in the lunge space ratio was associated with a decreased proportion of sideways directed head lunge movements (Figure $1 \mathrm{~F}$ ) by as much as $54.77 \%$, whereas an effect of the bed length ratio on this behavior was not statistically supported (Table 4).

\section{Lying Position}

An increase in the bed length ratio was associated with an increased proportion of lying without physical contact with cubicle elements (Figure 2A) by up to
$55.91 \%$ (Table 4). Consequently, an increase in the bed length ratio was associated with a decreased proportion of lying with physical contact with the curb board (Figure 2B) or the partitions by as much as $41.07 \%$ and $12.82 \%$, respectively (Table 4 ). An effect of the lunge space ratio on the observed lying positions was not statistically supported (Table 4).

\section{Joint Lesions}

The proportion of cows with moderate and severe lesions was low (carpal joints: $10 / 144=7 \%$ and $7 / 144$ $=5 \%$, respectively; tarsal joints: $19 / 144=13 \%$ and $1 / 144=1 \%$, respectively). Therefore, minor, moderate, and severe lesions were combined and the presence or absence of lesions at each type of joint was analyzed. An effect of the bed length ratio on the presence of carpal joint lesions (Figure 3A) was not statistically supported, whereas an increase in the bed length ratio was associated with a decreased presence of tarsal joint lesions (Figure 3B) by as much as $40.76 \%$ (Table 4 ). An effect of the lunge space ratio of wall-facing or headto-head cubicles on joint lesions was not statistically supported (Table 4).

\section{DISCUSSION}

In general, the cubicle dimensions on the farms in the present study were sufficiently large for the cows up to $163 \mathrm{~cm}$ withers height to perform species-specific lying down and standing up movements. Non-species-specific movements were observed only for standing up events and only in 15/655 (2\%) of the cases. However, the bed length ratio substantially affected the behavior during lying down and standing up, the cow's lying position, and the presence of lesions at the tarsal joints. Moreover, the lunge space ratio affected the proportion of sideways directed head lunge movements during standing up movements. The observed effects were consistent between farms despite the large variation in cubicle size and design between farms (seen in the model estimates, 95\% confidence intervals, and $P$-values). They were also consistent across the different breeds. We found no indication that the breeds of our study differed in the variation of the body size measurements (Supplemental Figure S1; https://doi.org/10.3168/jds.2019-16464), although we had expected to see differences in body proportions (e.g., differing body widths at the same withers height).

An increase in the bed length ratio was associated with a decreased proportion of lying down movements with repeated head pendulum movements and repeated stepping with front legs. Repeated head pendulum movements are considered to reflect hesitation by the animal 
A

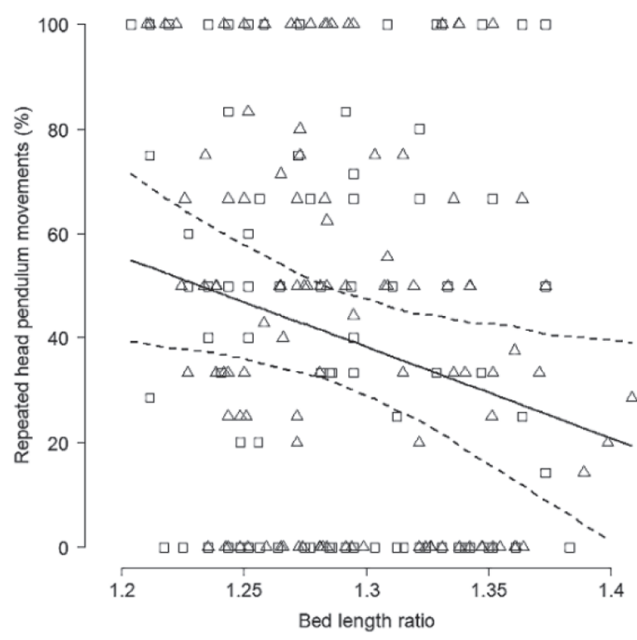

C
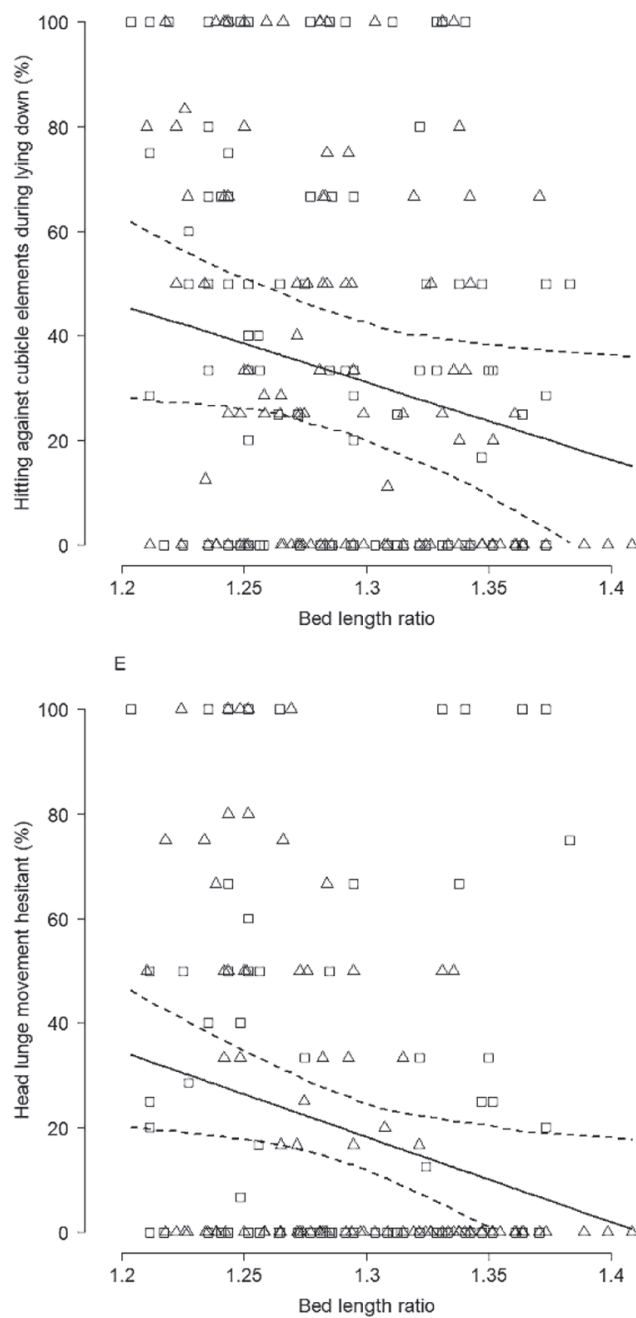

B

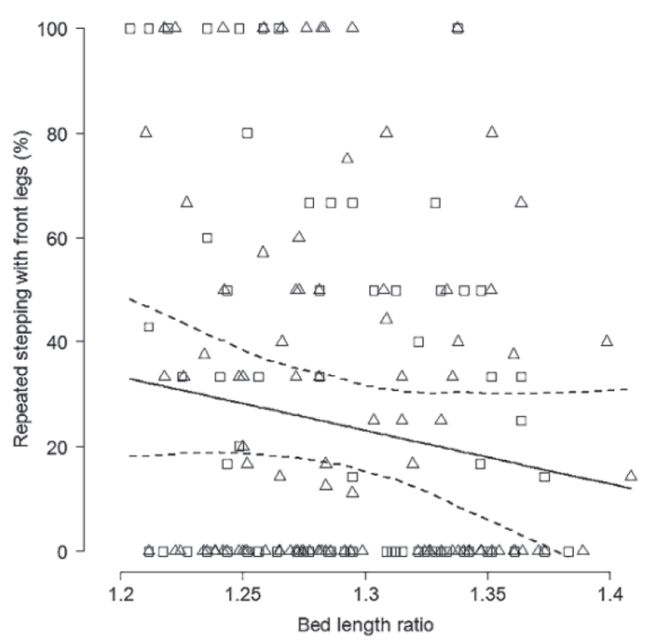

D
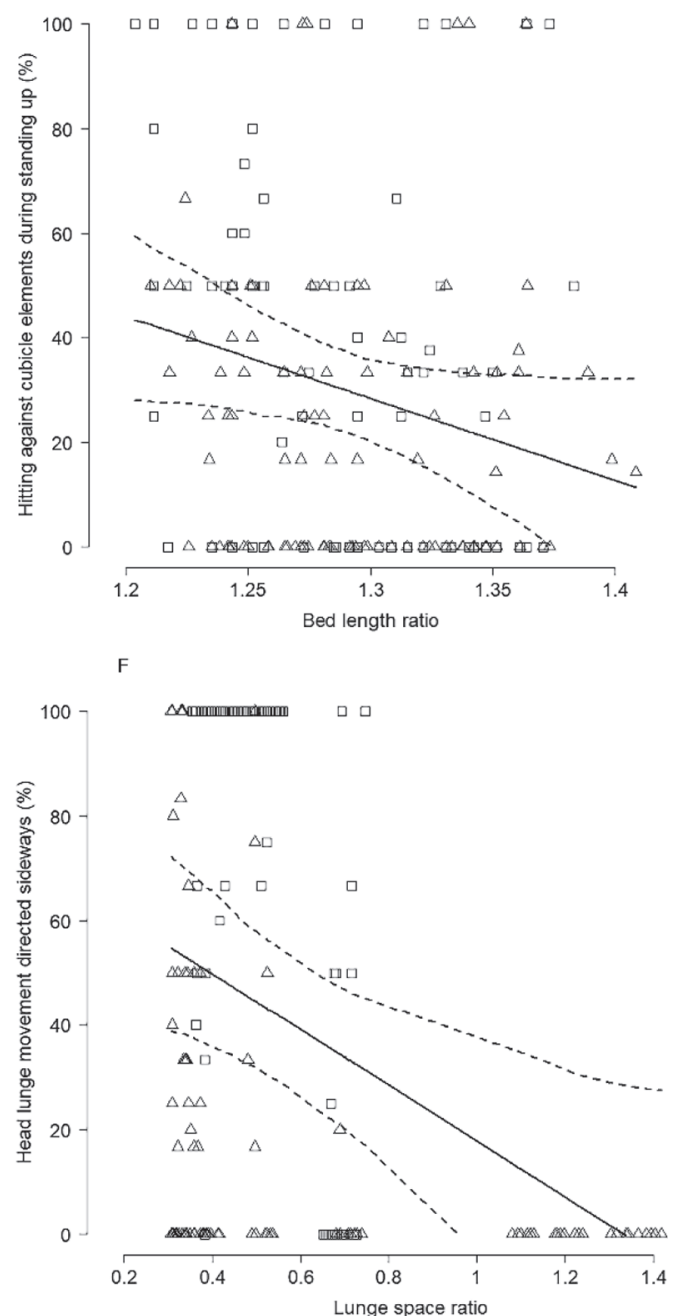

Figure 1. Proportion of (A) repeated head pendulum movements, (B) repeated stepping with front legs before lying down movements, (C) hitting against cubicle elements during lying down movements, (D) hitting against cubicle elements during standing up movements, (E) hesitant head lunge movements in dependence of the bed length ratio, and $(\mathrm{F})$ head lunge movements directed sideways for standing up movements in dependence of the lunge space ratio. Data of individual cows in wall-facing cubicles $(\square)$ and head-to-head cubicles $(\Delta)$ are shown in addition to model estimates (solid line) with $95 \%$ CI (dashed lines). 

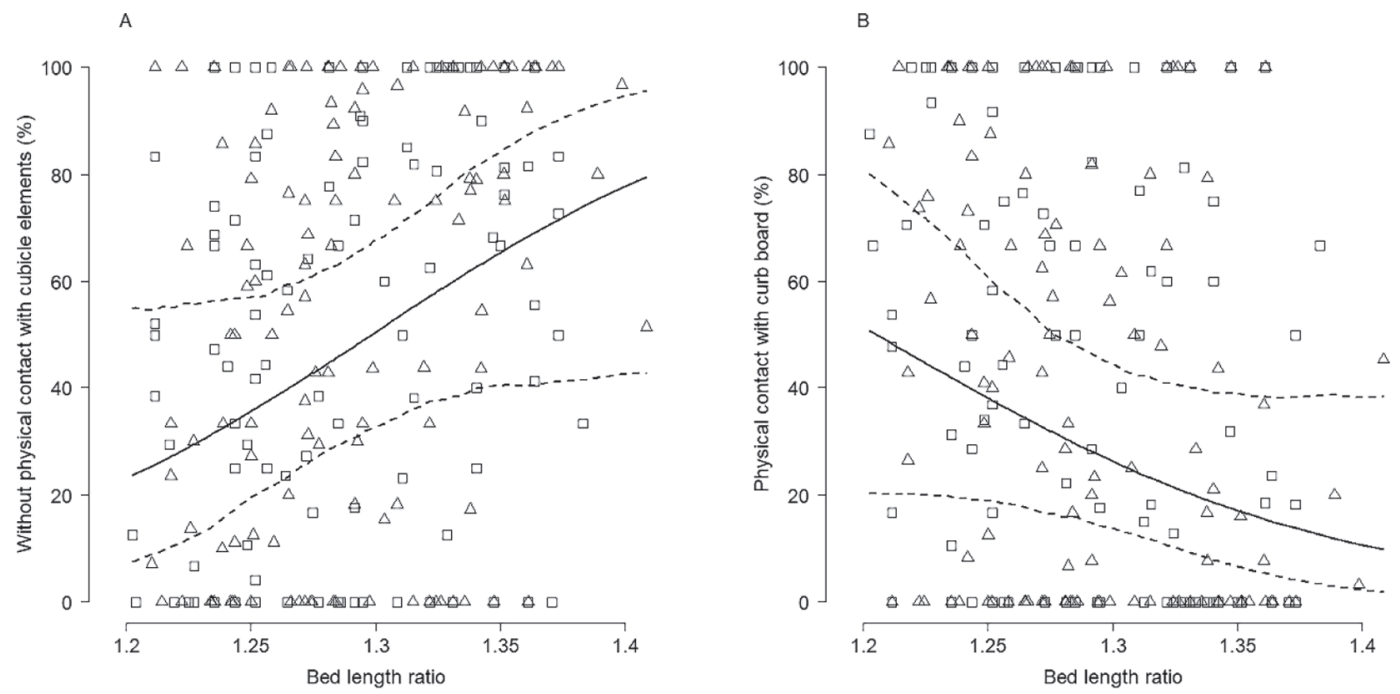

Figure 2. Proportion of lying positions (A) without physical contact with cubicle elements and (B) with physical contact with the curb board in dependence of the bed length ratio. Data of individual cows in wall-facing cubicles $(\square)$ and head-to-head cubicles $(\Delta)$ are shown in addition to model estimates (solid line) with $95 \%$ CI (dashed lines).

to lie down due to a lack of housing comfort (Haley et al., 2000) and were reported as being more frequent in smaller compared with larger cubicles (Hörning and Tost, 2001). Repeated stepping in place rarely occurs on pasture; however, in cubicles, it may be induced by insufficient space or past painful experiences when lying down (Kämmer, 1979) and was observed more frequently in larger compared with smaller cows (Gisiger, 2003). Moreover, the proportion of cows shifting backward before or during standing up decreased with an increase in the bed length ratio. Shifting backward, which means that the pelvis must be moved with a larger stoop and more effort than normal (Hoffmann and Rist, 1975), indicates inappropriate cubicle design (Potterton et al., 2011).

The proportion of hitting against cubicle elements, which is assumed to be potentially painful for the animals (Kämmer, 1979), also decreased with an increase in the bed length ratio during both standing up and lying down movements. This finding is in line with previous studies on dairy cows and finishing bulls that showed this behavior more often in smaller compared
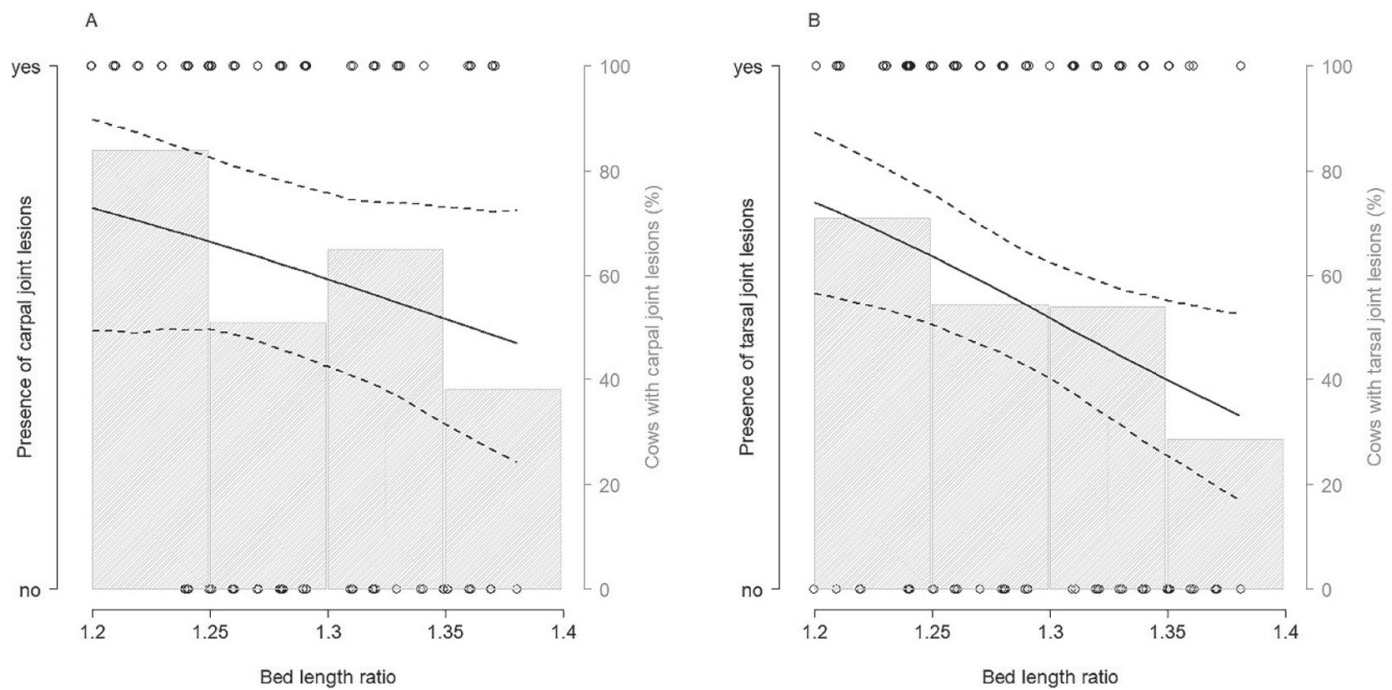

Figure 3. Presence of (A) carpal joint lesions and (B) tarsal joint lesions in dependence of the bed length ratio. Data of individual cows (O) are shown in addition to model estimates (solid line) with 95\% CI (dashed lines), as well as the proportion of cows with lesions for the bed length ratios of $1.200-1.249,1.250-1.299,1.300-1.349$, and $1.350-1.420$ (gray bars). 
with larger cubicles (Kämmer and Tschanz, 1975; Hörning and Tost, 2001; Gygax et al., 2005).

The head lunge is crucial for standing up movements and is usually carried out smoothly and directed straight forward (Kämmer and Schnitzer, 1975). In cubicle housing systems, Gygax et al. (2005) found a decrease in hesitant head lunge movements following an enlargement of the total cubicle length. Accordingly, in the present study, an increase in the bed length ratio was associated with a decreased proportion of hesitant head lunge movements. By contrast, an effect of the lunge space ratio was not statistically supported, which possibly reflected that the cows were able to direct the head lunge sideways (Bickert and Smith, 1998). In fact, the proportion of sideways directed head lunge movements decreased with an increase in the lunge space ratio. Lateral head lunge movements, which can lead to tension in the neck muscles, are an adaptation to insufficient lunge space and are rarely performed on pasture (Kämmer and Schnitzer, 1975). These results emphasize the importance of an adequate lunge space. In the present study, sideways directed head lunge movements occurred only in wall-facing cubicles and in head-to-head cubicles with a front rail height below $85 \mathrm{~cm}$. This finding indicated that the lunge space in the wall-facing cubicles was insufficient on the study farms and that an appropriate modification would be to position the front rail in head-to-head cubicles at a height of at least $85 \mathrm{~cm}$ above the bed surface.

An increase in the bed length ratio was associated with an increased proportion of observations of lying positions without physical contact with cubicle elements. Nonetheless, even with a bed length ratio of 1.4, the estimated proportion reached only $79.51 \%$; this finding emphasizes the importance of an adequate bed space (Bickert and Cermak, 1997; Cook and Nordlund, 2009). Potterton et al. (2011) identified cubicle designs in which cows come into contact with the cubicle elements during recumbency as a risk factor associated with hair loss, ulceration, and swelling at the tarsal joints. Accordingly, an increase in the bed length ratio was associated with decreased proportions of lying with physical contact with the curb board and the presence of tarsal joint lesions. Similarly, tarsal joint lesions were found more frequently in cubicles with shorter bed lengths and in larger cows (Kielland et al., 2009). Conversely, an effect of the bed length ratio on carpal joint lesions was not statistically supported, even though lesions were evident in $60 \%$ of the cows. This finding is supported by the generally low proportion of lying with physical contact with the brisket board, and suggests that the occurrence of carpal joint lesions was probably due to other causes, such as falling on slippery floors (Zaffino Heyerhoff et al., 2014).
To summarize, the bed length ratio strongly affected the cows' lying down and standing up movements, their lying positions, and the presence of lesions at the tarsal joints. However, enlarged cubicle dimensions can have negative effects on the cleanliness of the bed surface and, accordingly, of the animals (Tucker et al., 2004; Martiskainen et al., 2007). Plesch and Knierim (2012) also reported an increase in teat soiling with increasing cubicle length, which possibly increases the threat of bacterial infections and the risk of clinical mastitis (Schreiner and Ruegg, 2003). Consequently, the dimensions of cubicles remain a matter of compromise between function (i.e., controlling the cows' positions and cleanliness) and cow comfort, particularly in herds with highly heterogeneous body sizes. Therefore, future research should also consider management-related factors to define practice-appropriate cubicle dimensions.

In conclusion, large-framed cows were restricted to a greater extent during lying down and standing up movements as well as in the recumbent position than smaller cows under the given cubicle dimensions. In view of the consistency of the obtained results, we recommend adjusting cubicles dimensions to the increase in cow body size related to breeding goals.

\section{ACKNOWLEDGMENTS}

We sincerely thank the farmers for their participation in the study. The authors have not stated any conflicts of interest.

\section{REFERENCES}

Abdi, H., and L. J. Williams. 2010. Principal component analysis. Wiley Interdiscip. Rev. Comput. Stat. 2:433-459. https://doi.org/ 10.1002/wics.101.

Bates, D., M. Mächler, B. Bolker, and S. Walker. 2015. Fitting linear mixed-effects models using lme4. J. Stat. Softw. 67:1-48. https:// doi.org/10.18637/jss.v067.i01.

Bewley, J. M., R. E. Boyce, J. Hockin, L. Munksgaard, S. D. Eicher, M. E. Einstein, and M. M. Schutz. 2010. Influence of milk yield, stage of lactation, and body condition on dairy cattle lying behaviour measured using an automated activity monitoring sensor. J. Dairy Res. 77:1-6. https://doi.org/10.1017/S0022029909990227.

Bickert, W. G., and J. Cermak. 1997. Housing considerations relevant to lameness of dairy cows. Pages 300-307 in Lameness of Cattle. 3rd ed. W. B. Saunders, Philadelphia, PA.

Bickert, W. G., and J. F. Smith. 1998. Freestall barn design and management for cow comfort. Kansas Agricultural Experiment Station Research Reports. https://doi.org/10.4148/2378-5977.3241.

Ceballos, A., D. Sanderson, J. Rushen, and D. M. Weary. 2004. Improving stall design: Use of 3-D kinematics to measure space use by dairy cows when lying down. J. Dairy Sci. 87:2042-2050. https: //doi.org/10.3168/jds.S0022-0302(04)70022-3.

Charlton, G. L., V. Bouffard, J. Gibbons, E. Vasseur, D. B. Haley, D. Pellerin, J. Rushen, and A. M. de Passillé. 2016. Can automated measures of lying time help assess lameness and leg lesions on tiestall dairy farms? Appl. Anim. Behav. Sci. 175:14-22. https://doi .org/10.1016/j.applanim.2015.02.011.

Cook, N. B., and K. V. Nordlund. 2009. The influence of the environment on dairy cow behavior, claw health and herd lameness 
dynamics. Vet. J. 179:360-369. https://doi.org/10.1016/j.tvjl.2007 .09.016.

Fregonesi, J. A., M. A. G. von Keyserlingk, C. B. Tucker, D. M. Veira, and D. M. Weary. 2009. Neck-rail position in the free stall affects standing behavior and udder and stall cleanliness. J. Dairy Sci. 92:1979-1985. https://doi.org/10.3168/jds.2008-1604.

FSVO. 2008. Animal Welfare Ordinance (TSchV, SR 455.1). Federal Food Safety and Veterinary Office FSVO, Bern, Switzerland. Accessed Jun. 8, 2020. https://www.admin.ch/opc/de/classified -compilation/20080796/index.html.

Fulwider, W. K., T. Grandin, D. J. Garrick, T. E. Engle, W. D. Lamm, N. L. Dalsted, and B. E. Rollin. 2007. Influence of free-stall base on tarsal joint lesions and hygiene in dairy cows. J. Dairy Sci. 90:3559-3566. https://doi.org/10.3168/jds.2006-793.

Galindo, F., and D. M. Broom. 2000. The relationships between social behaviour of dairy cows and the occurrence of lameness in three herds. Res. Vet. Sci. 69:75-79. https://doi.org/10.1053/rvsc.2000 .0391 .

Gisiger, E. 2003. Evaluation der Körpermasse von Milchkühen zur Ableitung der Mindestabemssungen von Liegeboxen. Diploma thesis. ETH Zürich, Switzerland.

Gygax, L., H. S. Westerath, J. Kuhlicke, B. Wechsler, and C. Mayer. 2005. Assessing cubicle dimensions for finishing bulls based on animal behaviour and cleanliness. Anim. Sci. 81:423-430. https:// doi.org/10.1079/ASC50280423.

Halekoh, U., and S. Højsgaard. 2014. A Kenward-Roger approximation and parametric bootstrap methods for tests in linear mixed models - The R package pbkrtest. J. Stat. Softw. 59:32. https:// doi.org/10.18637/jss.v059.i09.

Haley, D. B., J. Rushen, and A. M. Passillé. 2000. Behavioural indicators of cow comfort: Activity and resting behaviour of dairy cows in two types of housing. Can. J. Anim. Sci. 80:257-263. https:// doi.org/10.4141/A99-084.

Hoffmann, H., and M. Rist. 1975. Tiergerechte und arbeitswirtschaftlich günstige Anbindevorrichtungen fur Kühe. Schweizerische Landwirtschufthche Monatshefte 53:119-126.

Hörning, B., and J. Tost. 2001. Multivariate Analyse möglicher Einflussfaktoren auf das Ruheverhalten von Milchkühen in Boxenlaufställen. In: Aktuelle Arbeiten zur artgemäßen Tierhaltung 2001, KTBL-Schrift 407. Kuratorium für Technik und Bauwesen in der Landwirtschaft e.V. (KTBL), Darmstadt, Germany.

Kämmer, P. 1979. Untersuchungen zur Tiergerechtheit und ihrer Bestimmung bei Boxenlaufstallhaltung von Milchkühen in der Schweiz. Doctoral thesis. Univerität Bern, Switzerland.

Kämmer, P. 1981. Tiergerechte Liegeboxen für Milchvieh. KTBLArbeitspapier 58. Kuratorium für Technik und Bauwesen in der Landwirtschaft e.V. (KTBL), Darmstadt, Germany.

Kämmer, P., and U. Schnitzer. 1975. Die Stallbeurteilung am Beispiel des Ausruhverhaltens von Milchkühen. Kuratorium für Technik und Bauwesen in der Landwirtschaft e.V. (KTBL), Darmstadt, Germany.

Kämmer, P., and B. Tschanz. 1975. Untersuchungen zur tiergerechten Haltung von Milchvieh in Boxenlaufställen. Schweizerische Landwirtschaftliche Forschung 14:203-223.

Kielland, C., L. E. Ruud, A. J. Zanella, and O. Østerås. 2009. Prevalence and risk factors for skin lesions on legs of dairy cattle housed in freestalls in Norway. J. Dairy Sci. 92:5487-5496. https://doi .org/10.3168/jds.2009-2293.

Lidfors, L. 1989. The use of getting up and lying down movements in the evaluation of cattle environments. Vet. Res. Commun. 13:307324. https://doi.org/10.1007/BF00420838.

Martin, P., and P. Bateson. 1993. Measuring Behavior: An Introductory Guide. 2nd ed. Cambridge University Press, Cambridge, UK.

Martiskainen, P., T. Koistinen, and J. Mononen. 2007. Cubicle dimensions affect resting-related behaviour, injuries and dirtiness of loose-housed dairy cows. Pages $175-180$ in Proc. 13th Int. Congr. Anim. Hyg. Estonian University of Life Sciences, Tartu, Estonia.

Norring, M., E. Manninen, A. M. de Passillé, J. Rushen, L. Munksgaard, and H. Saloniemi. 2008. Effects of sand and straw bedding on the lying behavior, cleanliness, and hoof and hock injuries of dairy cows. J. Dairy Sci. 91:570-576. https://doi.org/10.3168/jds .2007-0452.

O'Driscoll, K., L. Boyle, and A. Hanlon. 2009. The effect of breed and housing system on dairy cow feeding and lying behaviour. Appl. Anim. Behav. Sci. 116:156-162. https://doi.org/10.1016/j applanim.2008.08.003

Plesch, G., and U. Knierim. 2012. Effects of housing and management conditions on teat cleanliness of dairy cows in cubicle systems taking into account body dimensions of the cows. Animal 6:13601368. https://doi.org/10.1017/S1751731112000031.

Potterton, S. L., M. J. Green, J. Harris, K. M. Millar, H. R. Whay, and J. N. Huxley. 2011. Risk factors associated with hair loss, ulceration, and swelling at the hock in freestall-housed UK dairy herds. J. Dairy Sci. 94:2952-2963. https://doi.org/10.3168/jds .2010-4084.

R Core Team. 2017. A Language and Environment for Statistical Computing. R Foundation for Statistical Computing, Vienna, Austria. Accessed Jun. 8, 2020. https://www.R-project.org/.

Rudolphi, B. 2008. Klasse statt Masse - Zusammenhänge von Grösse, Gewicht und Leistungen bei Milchkühen. in Proc. 26. Tag des Milchviehalters, LKV Sachsen-Anhalt e.V., Bernburg und Iden, Germany.

Schönmuth, G., and M. Löber. 2006. Beziehungen zwischen Körpergröße und Leistungen beim Rind. Zuchtungskunde 78:324-335.

Schreiner, D. A., and P. L. Ruegg. 2003. Relationship between udder and leg hygiene scores and subclinical mastitis. J. Dairy Sci. 86:3460-3465. https://doi.org/10.3168/jds.S0022-0302(03)73950 -2 .

Sieber, M., A. E. Freeman, and D. H. Kelley. 1988. Relationships between body measurements, body weight, and productivity in Holstein dairy cows. J. Dairy Sci. 71:3437-3445. https://doi.org/10 .3168/jds.S0022-0302(88)79949-X.

Siivonen, J., S. Taponen, M. Hovinen, M. Pastell, B. J. Lensink, S. Pyörälä, and L. Hänninen. 2011. Impact of acute clinical mastitis on cow behaviour. Appl. Anim. Behav. Sci. 132:101-106. https:// doi.org/10.1016/j.applanim.2011.04.005

Tucker, C. B., D. M. Weary, and D. Fraser. 2004. Free-stall dimensions: Effects on preference and stall usage. J. Dairy Sci. 87:12081216. https://doi.org/10.3168/jds.S0022-0302(04)73271-3.

Weary, D. M., and I. Taszkun. 2000. Hock lesions and free-stall design. J. Dairy Sci. 83:697-702. https://doi.org/10.3168/jds.S0022 -0302(00)74931-9.

Weigele, H. C., L. Gygax, A. Steiner, B. Wechsler, and J.-B. Burla. 2018. Moderate lameness leads to marked behavioral changes in dairy cows. J. Dairy Sci. 101:2370-2382. https://doi.org/10.3168/ jds.2017-13120.

Westin, R., A. Vaughan, A. M. de Passillé, T. J. DeVries, E. A. Pajor, D. Pellerin, J. M. Siegford, E. Vasseur, and J. Rushen. 2016. Lying times of lactating cows on dairy farms with automatic milking systems and the relation to lameness, leg lesions, and body condition score. J. Dairy Sci. 99:551-561. https://doi.org/10.3168/jds .2015-9737.

Zaffino Heyerhoff, J. C., S. J. LeBlanc, T. J. DeVries, C. G. R. Nash, J. Gibbons, K. Orsel, H. W. Barkema, L. Solano, J. Rushen, A. M. de Passillé, and D. B. Haley. 2014. Prevalence of and factors associated with hock, knee, and neck injuries on dairy cows in freestall housing in Canada. J. Dairy Sci. 97:173-184. https://doi .org/10.3168/jds.2012-6367.

\section{ORCIDS}

L. Gygax @ https://orcid.org/0000-0001-8546-2930

B. Wechsler (ㄴ) https://orcid.org/0000-0002-9022-5988

J.-B. Burla @ https://orcid.org/0000-0001-7470-5781 